\title{
Impact of new observations on improved understanding of the Paleocene-Eocene Thermal Maximum
}

\author{
Mingsong Li ${ }^{1}$, LeE R. KUMP ${ }^{1}$, OluWASEyi AJAYi ${ }^{1}$, \\ DANIEL AMRHEIN ${ }^{2}$, GREGORY J. HAKIM ${ }^{3}$, STEVEN B. \\ MALEVICH $^{4}$, Chris POULSEN ${ }^{5}$, ANDY RIDGWELL ${ }^{6}$, \\ ROBERT TARDIF ${ }^{3}$, JESSICA E. TIERNEY $^{4}$, FUQING \\ $\mathrm{ZHANG}^{7}$, JIANG ZHU \\ ${ }^{1}$ Department of Geosciences, Pennsylvania State University, \\ University Park, PA, USA; mul450@psu.edu \\ ${ }^{2}$ National Center for Atmospheric Research, Boulder, CO, \\ USA \\ ${ }^{3}$ Department of Atmospheric Sciences, University of \\ Washington, Seattle, WA, USA \\ ${ }^{4}$ Department of Geosciences, University of Arizona, Tucson, \\ AZ, USA \\ ${ }^{5}$ Department of Earth and Environmental Sciences, \\ University of Michigan, Ann Arbor, MI, USA \\ ${ }^{6}$ Department of Earth Sciences, University of California at \\ Riverside, Riverside, CA, USA \\ ${ }^{7}$ Department of Meteorology, The Pennsylvania State \\ University, University Park, PA, USA \\ Collection of proxy data from field sites is a fundamental \\ step to decipher the history of Earth's climate system. Field- \\ site selection is based on a number of factors, including the \\ availability of rock of the targeted age, whether the rocks are \\ likely to contain proxy-containing materials little altered by \\ diagenesis and weathering, and whether a particular region \\ has been undersampled in the past. One factor that has only \\ been qualitatively assessed is the impact that new proxy \\ information from a particular field site will have on our \\ understanding of the regional or global climate state. Here we \\ present an ensemble-based Kalman filter (EnKF) method for \\ the estimate of this observation impact factor. The methods \\ are verified with a case study using TEX $_{86}$ and $\delta^{18} \mathrm{O}$ data, \\ proxies of sea surface temperature from over 20 sites, and a \\ 150-member ensemble from an Earth system model of \\ intermediate complexity (cGENIE) for the Paleocene-Eocene \\ Thermal Maximum (PETM, ca. $56 \mathrm{Ma}$ ). A statistically \\ significant relationship between impact factor and data-model \\ misfit reduction validates the impact factor results \\ independently. This new approach may provide supporting \\ justification for the selection of particular field sites for future \\ observations in paleoclimate studies, e.g., associated with the \\ Integrated Ocean and Continental Scientific Drilling \\ Programs.
}

